\title{
Ginkgolic acid inhibits proliferation and migration of human hepatocellular carcinoma cells by inducing G0/G1 cell cycle arrest
}

\author{
Jiayu Chen ${ }^{\mathrm{a}, \mathrm{b}}$, Rui Wang ${ }^{\mathrm{a}}$, Ying $\mathrm{Li}^{\mathrm{a}, \mathrm{c}}$, Chunhe $\mathrm{Li}^{\mathrm{d}}$, Tao Liu ${ }^{\mathrm{d}}$, Yi Xin ${ }^{\mathrm{e}}$, Yiling $\mathrm{Li}^{\mathrm{b}, *}$, Dianbao Zhang ${ }^{\mathrm{a}, *}$ \\ ${ }^{a}$ Department of Stem Cells and Regenerative Medicine, Key Laboratory of Cell Biology, National Health \\ Commission of China and Key Laboratory of Medical Cell Biology, Ministry of Education of China, China \\ Medical University, Shenyang 110122 China \\ b Department of Medicine, Division of Gastroenterology, First Affiliated Hospital of China Medical \\ University, Shenyang 110015 China \\ c Department of Pathology, Affiliated Hospital of Jining Medical University, Jining 272029 China \\ d Department of Natural Products Chemistry, School of Pharmacy, China Medical University, Shenyang \\ 110122 China \\ e School of Management, Tianjin University of Traditional Chinese Medicine, Tianjin 301617 China
}

*Corresponding authors, e-mail: zhangdianbao@gmail.com, lyl-72@163.com

Received $20 \mathrm{Jul} 2020$

Accepted 26 Oct 2020

\begin{abstract}
Hepatocellular carcinoma (HCC) is a common cancer worldwide with high morbidity and mortality. Ginkgolic acid (GA) is a natural compound obtained from leaves and seed coats of Ginkgo biloba L., and it has been reported to have various bioactivities. However, the effects of GA on HCC cell cycle distribution and the mechanisms involved are still unknown. By CCK-8 assay and Transwell assay, the cell viability and migration of HCC cells were shown to be inhibited significantly by GA in a concentration-dependent manner. By cell cycle analysis and western blot, the cell cycle arrest at G0/G1 phase was shown to contribute to the inhibitory effects of GA. Furthermore, the phosphorylation of p38 MAPK was found to be elevated upon GA treatment as analyzed by western blot. Thus, GA inhibited cell proliferation and migration of HCC cells by inducing G0/G1 cell cycle arrest via p38 MAPK activation, indicating GA as an agent candidate for HCC treatment.
\end{abstract}

KEYWORDS: ginkgolic acid, hepatocellular carcinoma, G0/G1 cell cycle arrest, p38 MAPK

\section{INTRODUCTION}

Liver cancer is the fourth common cause of cancerrelated death around the world [1]. The cases of liver cancer continue increasing due to the growth of population and aging, despite the slowly decreased global age-standardized incidence rate (ASIR) from 1990 to 2015 [2]. Hepatocellular carcinoma (HCC) is a primary type of liver cancer, accounting for over $80 \%$ of the total [3]. The incidence rate and mortality of HCC are different in various parts of the world due to the diversity of environmental and medical conditions; it is serious in low-resource or middle-resource countries [3]. The prognosis of HCC is poor in all regions of the world. In the United States, 2 year survival rate is less than $50 \%$, and 5 year survival rate is only $10 \%$ [4]. At present, there are several treatment options for HCC according to the size, number and the situation of invasion, and metastasis, mainly including surgical therapies, tumor ablation, transarterial therapies, and systemic therapies [1]. So far, only two kinds of systemic drugs, Sorafenib and Lenvatinib, are used in first-line therapy; but the therapeutic effects are not satisfactory $[5,6]$. It is necessary to discover novel agent candidates for HCC therapy.

Ginkgo biloba L. is an ancient gymnosperm species distributed around the world and widely used in traditional Chinese medicine [7]. Ginkgolic acid (GA) is an alkylphenol constituent extracted from the leaves and seed coats of Ginkgo biloba [8]. GA had the potential of anti-inflammation, anti-HIV, anti-diabetes, anti-bacterial, and anti-virus [9-13]. For cancer, GA presented inhibitory effects on the viability of pancreatic cancer, colon cancer, and lung cancer cells, with little cytotoxic effect on noncancer cells [14-16]. Recently, GA was found to induce HCC cell death via apoptosis, autophagy 
and mitochondrial pathway [17]. The inhibition of $\mathrm{HGF} / \mathrm{c}-\mathrm{Met}$ signaling was involved in GA-induced suppression of HepG2 cells invasion [18]. However, the specific mechanisms in HCC cells upon GA treatment have not been determined.

In this study, the anti-HCC effects of GA were determined by cell viability, migration, cell cycle distribution assays; and the activation of MAPKs signaling was detected by western blot in HCC cells upon GA treatment. This investigation might provide a novel agent candidate for the future therapy of HCC, as well as the underlying mechanisms.

\section{MATERIALS AND METHODS}

\section{Cell culture and reagents}

Human liver cancer cell lines HepG2 and Huh-7 were cultured in Dulbecco's Modified Eagle's medium (DMEM, high glucose, HyClone, Beijing, China) with 10\% FBS (Biological Industries, Israel) and $1 \%$ Penicillin-Streptomycin solution (HyClone) at $37^{\circ} \mathrm{C}$ with $5 \% \mathrm{CO}_{2}$ and $95 \%$ relative humidity. GA was purchased from MCE (Shanghai, China) and dissolved in $100 \mathrm{mM}$ dimethyl sulfoxide (DMSO) and stored at $-20^{\circ} \mathrm{C}$ for use. Working solutions of GA were prepared in DMEM at the indicated concentrations.

\section{CCK-8 assay}

The cells were dissociated by trypsin-EDTA solution (Biological Industries) and seeded onto 96well plates. After incubation for $24 \mathrm{~h}$ at $37^{\circ} \mathrm{C}$, the medium was replaced with new medium containing different concentrations of GA $(0,12.5,25,50$, $100,200$ and $300 \mu \mathrm{M})$. Following incubation for another 24 h, $10 \mu$ l CCK-8 reagent (Meilun, Dalian, China) was added into each well and incubated for $30 \mathrm{~min}$ at $37^{\circ} \mathrm{C}$. The absorbance value at wavelength $450 \mathrm{~nm}$ was measured using a microplate reader (iMRAK, Bio-Rad, Hercules, CA, USA), with a reference wavelength at $630 \mathrm{~nm}$.

\section{Cell migration assay}

After incubation with GA for $24 \mathrm{~h}$, the cells were harvested and added into the upper chamber of Transwell (3422, Corning, NY, USA) at $2 \times 10^{5}$ cells/well in $200 \mu \mathrm{l}$ serum-free DMEM medium. $500 \mu \mathrm{l}$ DMEM with $10 \%$ FBS was added into the lower chamber. After incubation for $48 \mathrm{~h}$, the cells residual in the upper chamber were scraped off by a cotton swab and other cells on the lower side of the chamber were fixed by $4 \%$ paraformaldehyde (Beyotime, Jiangsu, China) for $10 \mathrm{~min}$ and stained by $0.1 \%$ crystal violet (Beyotime) for $10 \mathrm{~min}$. Subsequently, the cells were imaged under a microscope (Observer A1, Carl Zeiss, Oberkochen, Germany).

\section{Cell cycle assay}

HepG2 cells were harvested into centrifuge tube and washed by cold PBS. After fixing in 70\% ethyl alcohol at $4^{\circ} \mathrm{C}$ overnight, the cells were washed by cold PBS again and then stained with propidium iodide (PI) and RNAse mixture (Beyotime) at $37^{\circ} \mathrm{C}$ for $30 \mathrm{~min}$ in the dark. The cell cycle distribution was analyzed by a Flow cytometer (Canto II, BD Bioscience, San Jose, CA, USA).

\section{Real-time PCR}

Total RNA was extracted with RNAiso Plus (TaKaRa, Dalian, China) according to the manufacturer's protocol. The RNA was analyzed and quantified by NanoDrop 2000c spectrophotometer (Thermo Fisher Scientific, Wilmington, DE, USA). Total RNA was reverse-transcribed into cDNA using GoScript Reverse Transcription System (Promega, Madison, WI USA) according to the manufacturer's protocol. The mRNA relative expression level was determined in the Applied Biosystems 7500 Real-Time PCR system using PowerUp SYBR Master Mix (Applied Biosystems, Shanghai, China). The reaction conditions were as followed: holding at $50^{\circ} \mathrm{C}$ for $2 \mathrm{~min}$, $95^{\circ} \mathrm{C}$ for $2 \mathrm{~min}$; 40 cycles at $95^{\circ} \mathrm{C}$ for $15 \mathrm{~s}, 60^{\circ} \mathrm{C}$ for $1 \mathrm{~min}$. The mRNA level was quantified using $\Delta \Delta \mathrm{Ct}$ method and ACTB served as an internal control. The primer sequences are as follows: CCNA2, forward primer: $5^{\prime}$-AACACTCACTGGCTTTTCATCT- ${ }^{\prime}$ and reverse primer: $5^{\prime}$-AACACTCACTGGCTTTTCATCT3'; CCNB1, forward primer: $5^{\prime}$-TTGGTCTGACTGCT TGCTCTT- $3^{\prime}$ and reverse primer: $5^{\prime}$-TTGGTCTG ACTGCTTGCTCTT-3'; CCNE1, forward primer: 5'AAGGAGCGGGACACCATGA- $3^{\prime}$ and reverse primer: 5'-ACGGTCACGTTTGCCTTCC-3'; ACTB, forward primer: $5^{\prime}$-TGGCACCCAGCACAATGAA-3' and reverse primer: 5'-CTAAGTCATAGTCCGCCTAGAA GCA-3'.

\section{Western blot}

HepG2 cells were lysed with RIPA (Beyotime) supplemented with PMSF and Complete Protease Inhibitor Cocktail (Roche, Shanghai, China) and the concentration of total protein was measured using BCA Protein Assay Kit (TaKaRa) according to the manufacturer's protocol. The protein was separated by $10 \%$ SDS-PAGE and transferred to PVDF membrane. After blocking with 5\% skim milk 
for $1 \mathrm{~h}$, the membranes were incubated with primary antibodies against CCNA2 (1:2000, Proteintech, Wuhan, China), CCNB1 (1:500, Proteintech), CCNE1 (1:2000, Proteintech), ERK (1:2000, CST, Shanghai, China), p-ERK (1:2000, CST), p38 MAPK (1:2000, CST), p-p38 MAPK (1:2000, CST), and GAPDH (1:10000, Proteintech) at $4{ }^{\circ} \mathrm{C}$ overnight followed by a wash with TBST for 3 times. The membranes were incubated with HRP-conjugated goat anti-rabbit IgG (1:5000, Proteintech) or goat anti-mouse IgG (1:5000, Proteintech) at room temperature for $1 \mathrm{~h}$ and then rinsed in TBST for 3 times. The protein expression levels were detected by Amersham ECL Prime Western Blotting Detection Reagent (GE Healthcare, Princeton, NJ, USA) using Tanon-5200 chemiluminescence detection system (Tanon, Shanghai, China). Protein gray values were analyzed by Image $\mathrm{J}$ software.

\section{Statistical analysis}

The data are presented as the mean \pm standard deviation (SD). Differences among groups were analyzed by Student's $t$-test. $p<0.05$ was considered to be statistically significant.

\section{RESULTS}

\section{GA inhibits cell viability of HCC cells}

In order to explore the effects of GA (Fig. 1A) on HCC proliferation, the cell viability was determined by CCK-8 assay. As shown in Fig. 1B and 1C, the cell viabilities of Huh-7 and HepG2 cells were significantly inhibited by GA $(50-300 \mu \mathrm{M})$ versus DMSO group in a concentration-dependent manner. Consistent with this data, the cell number was obviously reduced by GA under phase-contrast microscope (Fig. 1D). These results proved the inhibitory effect of GA on HCC cell proliferation.

\section{GA inhibits cell migration of HCC cells}

Cell migration is crucial in the mediation of cancer metastasis [19]. In order to investigate the role of GA on the migration of HCC cells, Transwell assay was conducted. As presented in Fig. 2, the migrated cell number was significantly reduced by GA treatment at 50 and $100 \mu \mathrm{M}$ in a concentrationdependent manner, indicating the remarkably suppressive effect of GA on HCC cells migration.

\section{Cell cycle arrest at G0/G1 phase induced by GA}

Cell cycle plays a key role in cancer treatment since the aberrant function of cell cycle regulators will result in uncontrolled cell proliferation [20]. To investigate whether GA can induce cell cycle arrest of HCC cells, we assessed the effect of GA on cell cycle distribution of HepG2 cells by PI staining followed by flow cytometry. The results revealed that GA increased the percentage of cells in G0/G1 phase (Fig. 3A and 3B). Furthermore, the mRNA levels of cell cycle regulator CCNA2, CCNB1 and CCNE1 were found to be inhibited by GA, and the decreased protein levels of the GA treated samples were verified by western blot analysis (Fig. 3C to $3 \mathrm{E})$. These results indicated that GA could induce G0/G1 cell cycle arrest of HCC cells by reducing CCNA2, CCNB1 and CCNE1 expression.

\section{p38 MAPK activation induced by GA}

Mitogen-activated protein kinase (MAPK) signaling pathway plays critical roles in some cancer-related activities including proliferation, differentiation and migration [21,22]. To investigate the potential mechanisms involved in the inhibitory effects of GA on HCC cells, ERK and p38 MAPK were analyzed by western blot. After treatment with GA, the phosphorylation of ERK and the total protein of ERK showed no significant differences compared to DMSO group. The phosphorylation of p38 MAPK was elevated and the total protein of p38 MAPK was decreased (Fig. 4), indicating that GA increased MAPK phosphorylation to inhibit proliferation and migration of HCC cells.

\section{DISCUSSION}

In this study, GA presented anticancer activity on HCC cells by arresting cell cycle at G0/G1 phase. Furthermore, the phosphorylation level of p38 MAPK was found to be significantly enhanced by GA. In previous studies, GA showed inhibitory effects on the growth of pancreatic cancer cells [14]. The invasion of colon cancer and lung cancer cells was inhibited through AMPK and PI3K/Akt signaling $[15,16]$. For liver cancer, GA could inhibit invasion and cause cell death $[17,18]$, which are consistent with our results. Here, we have discovered the cell cycle regulation by GA and the involvement of MAPK signaling. Moreover, the cytotoxicity of GA in primary hepatocytes from rats was lower than that in HepG2 cells $[23,24]$, indicating GA as a prospective agent candidate for the treatment of HCC.

Cell cycle regulation plays important roles in various cellular events. Mistakes, such as mutation, overexpression or elimination in cell cycle regulation or its checkpoints, may lead to the development of malignant cells [25]. Here, we showed that 
A

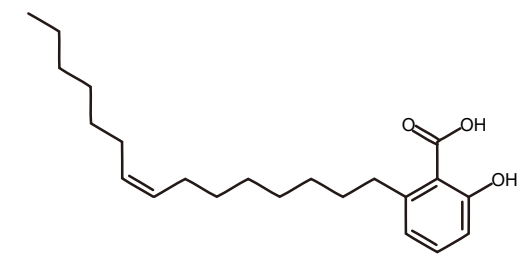

B
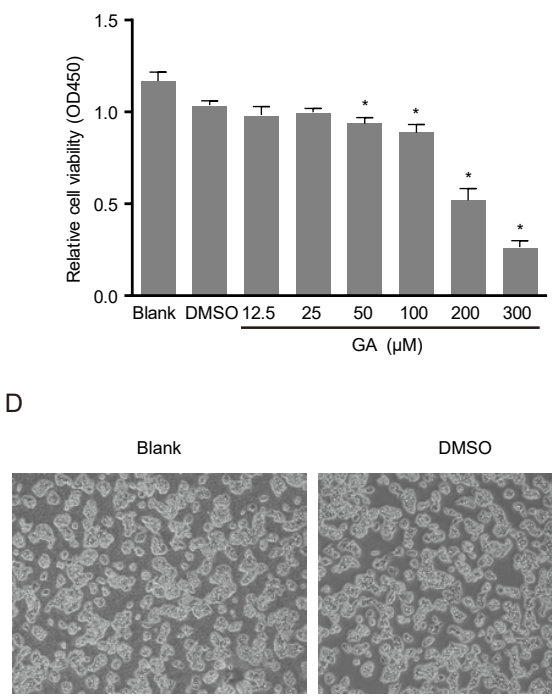

C

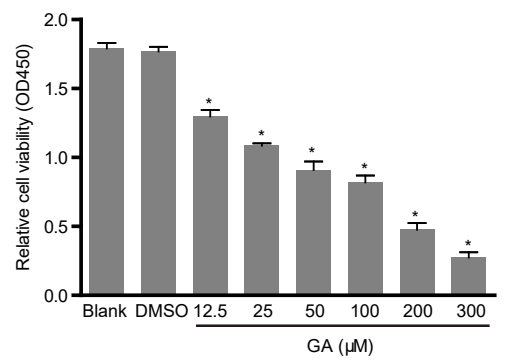

$\mathrm{GA}(50 \mu \mathrm{M})$

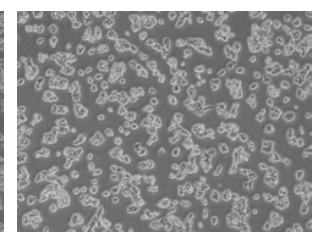

$\mathrm{GA}(100 \mu \mathrm{M})$

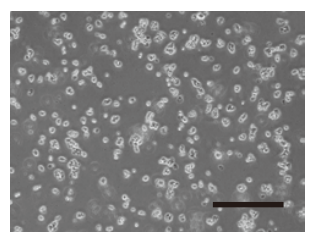

Fig. 1 HCC cell viability was inhibited by GA. (A) The chemical structure of GA. (B) The cell viability of Huh-7 cells was analyzed by CCK-8 assay. (C) The cell viability of HepG2 cells was analyzed by CCK-8 assay. * $p<0.05$ compared with DMSO group. (D) The representative images of HepG2 cells treated with GA at 50 and $100 \mu \mathrm{M}$, under phase-contrast microscope. Blank indicates cells without treatment. Bar indicates $100 \mu \mathrm{m}$.
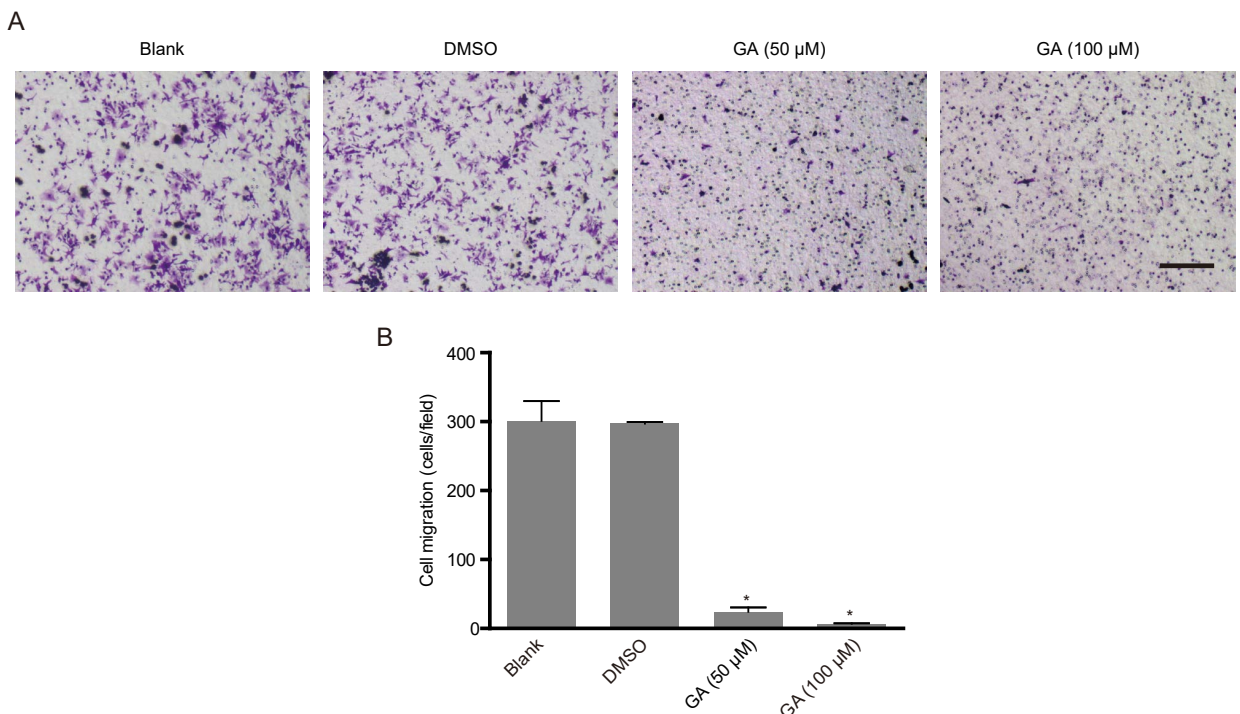

Fig. 2 HCC cell migration was inhibited by GA. (A) The HepG2 cells were treated with GA and the cell migration was determined by Transwell assay. Bar indicates $100 \mu \mathrm{m}$. (B) The migrated cell numbers were analyzed by Image $\mathrm{J}$ software. Blank indicates cells without treatment. * $p<0.05$ compared with DMSO group. 


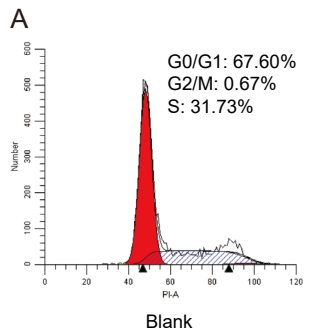

B
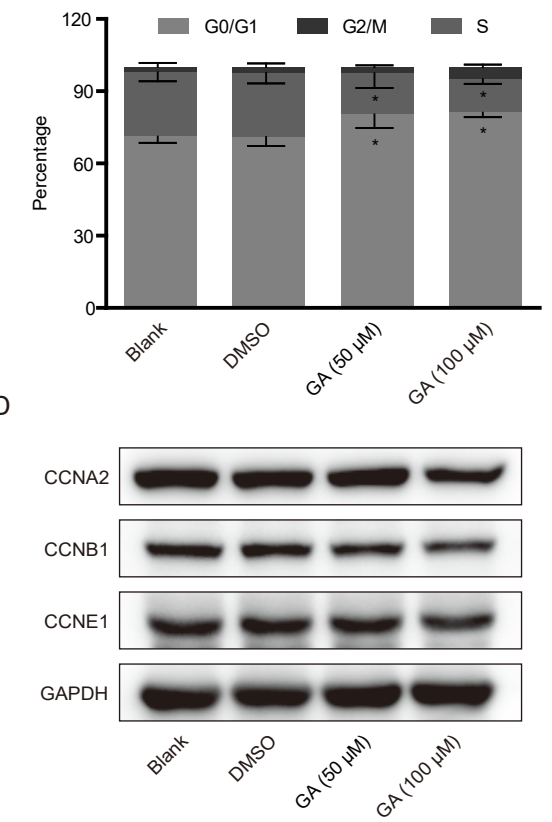

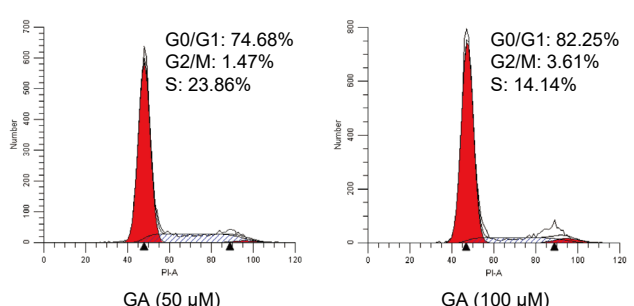

C

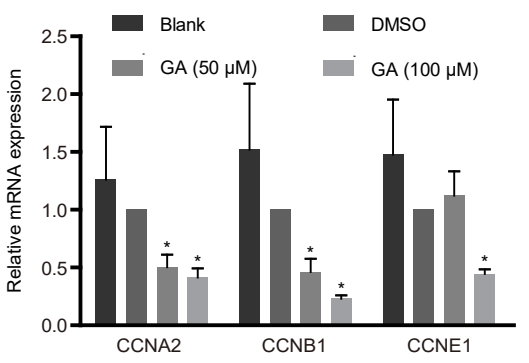

$E$

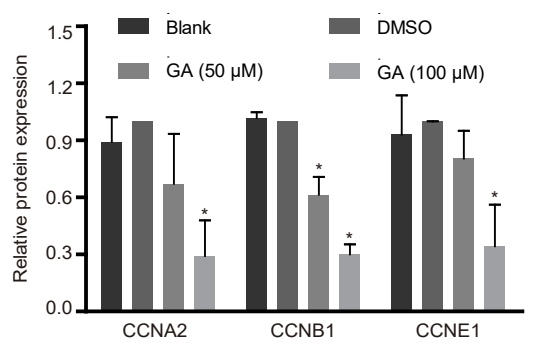

Fig. 3 GA induced cell cycle arrest in HCC cells. HepG2 cells were treated with GA at indicated concentrations. (A) The cell cycle distribution was analyzed by PI staining followed by flow cytometry. (B) The statistical analysis of cell cycle data. (C) The mRNA levels of CCNA2, CCNB1 and CCNE1 were analyzed by real-time PCR. (D) The protein levels of these genes were determined by western blot. (E) The images of western blot were analyzed by Image J software. Blank indicates cells without treatment. * $p<0.05$ compared with DMSO group.

A

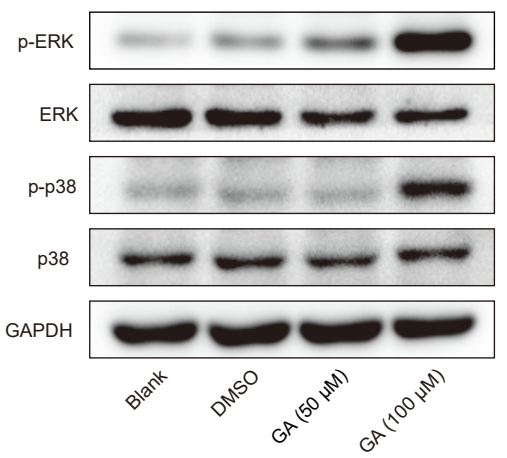

B

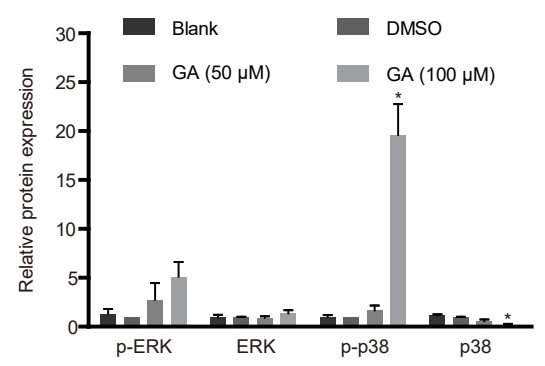

Fig. 4 The activation of p38 MAPK by GA treatment. HepG2 cells were treated with GA at indicated concentrations. (A) The total and phosphorylation protein levels of ERK and p38 MAPK were analyzed by western blot. (B) The images of western blot were analyzed by Image $\mathrm{J}$ software. Blank indicates cells without treatment. * $p<0.05$ compared with DMSO group. 
GA induced G0/G1 arrest in HepG2 cells, with the depression of mRNA and protein expression level of CCNA2, CCNB1 and CCNE1. During cell cycle progression, CCNE1 begins to accumulate in late G1 phase, reaches the maximum at G1/S transition and decreases during S phase [26], thus controlling the timing of G1/S transition [27]. For HCC, CCNE1 and CDK2 are crucial to the initiation instead of progression. The overexpression of CCNE1 will cause chromosome instability in liver cells, which makes it a high risk to lead to HCC in mouse $[28,29]$. Besides, CCNA2 has been reported to induce the transition in both G1/S and G2/M and promotes invasion and migration of non-small cell lung carcinoma cells [30,31]. In this study, the treatment with GA reduces the expression of CCNE1 and CCNA2 in HCC cells, leading to cell cycle arrest at G0/G1 phase, thus inhibiting cell proliferation and migration.

MAPK signaling pathways are essential for cell growth in physiological and pathological processes [32]. There are 3 main members of MAPK family in mammalian species: ERK, p38 MAPK and JNK [33]. The activation of p38 MAPK and JNK is related to apoptosis, inflammation and growth [34]. ERK could induce cell death [35]. Increasing phosphorylation levels of p38 MAPK in HCC tissues is positively associated with tumor size and the formation of satellite tumors; while JNK phosphorylation will antagonize the promoting effect of pp38 MAPK in human liver cancer [36]. In contrast, p38 $\alpha$ phosphorylation pathway targeting Hsp27 has been inversely correlated with tumor size, invasion, and tumor stages of human HCC [37]. Our study showed that GA increased p38 MAPK phosphorylation and inhibited the growth of HCC cells. Thus, we concluded that MAPKs signaling activation was involved in the anti-HCC activity of GA.

For HCC treatment, several agents targeting various pathways are under research. Sorafenib is the only approved targeted drug, but with serious side effects and limited efficacy [38]. $\gamma$-tocotrienol was proven to inhibit AKT/mTOR pathway to reduce angiogenesis in HCC mice model [39]. In a previous study, GA extracted from Ginkgo biloba leaves presented inhibitory effect on STAT3 activation, which was considered to be a potential therapeutic target in HCC [40-42]. Considering the MAPK activation found in this study, GA might also be a multitargeting agent.

In summary, the presented data proved that GA inhibited HCC cell viability and migration by inducing cell cycle arrest at G0/G1 phase, partly through p38 MAPK signaling activation. GA is a novel agent candidate for HCC treatment.

Acknowledgements: This work is funded by Liaoning Innovation and Entrepreneurship Training Program (201710159000101), Foundation of China Medical University (XZR20160022) and National Natural Science Foundation of China (81703102).

\section{REFERENCES}

1. Villanueva A (2019) Hepatocellular carcinoma. $N$ Engl J Med 380, 1450-1462.

2. Fitzmaurice C, Allen C, Barber RM, Barregard L, Bhutta ZA, Brenner H, Dicker DJ, Chimed-Orchir O, et al (2017) Global, regional, and national cancer incidence, mortality, years of life lost, years lived with disability, and disability-adjusted life-years for 32 cancer groups, 1990 to 2015: a systematic analysis for the global burden of disease study. JAMA Oncol 3, 524-548.

3. Yang JD, Hainaut P, Gores GJ, Amadou A, Plymoth A, Roberts LR (2019) A global view of hepatocellular carcinoma: trends, risk, prevention and management. Nat Rev Gastroenterol Hepatol 16, 589-604.

4. Golabi P, Fazel S, Otgonsuren M, Sayiner M, Locklear CT, Younossi ZM (2017) Mortality assessment of patients with hepatocellular carcinoma according to underlying disease and treatment modalities. Medicine (Baltimore) 96, e5904.

5. Llovet JM, Ricci S, Mazzaferro V, Hilgard P, Gane E, Blanc JF, de Oliveira AC, Santoro A, et al (2008) Sorafenib in advanced hepatocellular carcinoma. $N$ Engl J Med 359, 378-390.

6. Kudo M, Finn RS, Qin S, Han KH, Ikeda K, Piscaglia F, Baron A, Park JW, et al (2018) Lenvatinib versus sorafenib in first-line treatment of patients with unresectable hepatocellular carcinoma: a randomised phase 3 non-inferiority trial. Lancet 391, 1163-1173.

7. van Beek TA, Wintermans MS (2001) Preparative isolation and dual column high-performance liquid chromatography of ginkgolic acids from Ginkgo biloba. J Chromatogr A 930, 109-117.

8. Jaggy H, Koch E (1997) Chemistry and biology of alkylphenols from Ginkgo biloba L. Pharmazie 52, 735-738.

9. Li M, Li B, Hou Y, Tian Y, Chen L, Liu S, Zhang N, Dong J (2019) Anti-inflammatory effects of chemical components from Ginkgo biloba L. male flowers on lipopolysaccharide-stimulated RAW264.7 macrophages. Phytother Res 33, 989-997.

10. Yoon SY, Lee JH, Kwon SJ, Kang HJ, Chung SJ (2018) Ginkgolic acid as a dual-targeting inhibitor for protein tyrosine phosphatases relevant to insulin resistance. Bioorg Chem 81, 264-269.

11. Hua Z, Wu C, Fan G, Tang Z, Cao F (2017) The 
antibacterial activity and mechanism of ginkgolic acid C15:1. BMC Biotechnol 17, ID 5.

12. Lu JM, Yan S, Jamaluddin S, Weakley SM, Liang Z, Siwak EB, Yao Q, Chen C (2012) Ginkgolic acid inhibits HIV protease activity and HIV infection in vitro. Med Sci Monit 18, BR293-298.

13. Campos D, Navarro S, Llamas-Gonzalez YY, Sugasti M, Gonzalez-Santamaria J (2020) Broad antiviral activity of ginkgolic acid against Chikungunya, Mayaro, Una, and Zika viruses. Viruses 12, ID 449.

14. Ma J, Duan W, Han S, Lei J, Xu Q, Chen X, Jiang Z, Nan L, et al (2015) Ginkgolic acid suppresses the development of pancreatic cancer by inhibiting pathways driving lipogenesis. Oncotarget 6, 20993-21003.

15. Qiao L, Zheng J, Jin X, Wei G, Wang G, Sun X, Li $X$ (2017) Ginkgolic acid inhibits the invasiveness of colon cancer cells through AMPK activation. Oncol Lett 14, 5831-5838.

16. Baek SH, Ko JH, Lee JH, Kim C, Lee H, Nam D, Lee J, Lee SG, et al (2017) Ginkgolic acid inhibits invasion and migration and TGF-beta-induced EMT of lung cancer cells through PI3K/Akt/mTOR inactivation. $J$ Cell Physiol 232, 346-354.

17. Qi QM, Xue YC, Lv J, Sun D, Du JX, Cai SQ, Li $\mathrm{YH}, \mathrm{Gu}$ TC, et al (2018) Ginkgolic acids induce HepG2 cell death via a combination of apoptosis, autophagy and the mitochondrial pathway. Oncol Lett 15, 6400-6408.

18. Li H, Meng X, Zhang D, Xu X, Li S, Li Y (2019) Ginkgolic acid suppresses the invasion of HepG2 cells via downregulation of $\mathrm{HGF} / \mathrm{c}-\mathrm{Met}$ signaling. Oncol Rep 41, 369-376.

19. Trepat X, Chen Z, Jacobson K (2012) Cell migration. Compr Physiol 2, 2369-2392.

20. Zheng K, He Z, Kitazato K, Wang Y (2019) Selective autophagy regulates cell cycle in cancer therapy. Theranostics 9, 104-125.

21. Reddy KB, Nabha SM, Atanaskova N (2003) Role of MAP kinase in tumor progression and invasion. Cancer Metastasis Rev 22, 395-403.

22. Giehl K (2005) Oncogenic Ras in tumour progression and metastasis. Biol Chem 386, 193-205.

23. Liu ZH, Zeng S (2009) Cytotoxicity of ginkgolic acid in HepG2 cells and primary rat hepatocytes. Toxicol Lett 187, 131-136.

24. Yao QQ, Li L, Xu MC, Hu HH, Zhou H, Yu LS, Zeng S (2018) The metabolism and hepatotoxicity of ginkgolic acid (17:1) in vitro. Chin J Nat Med 16, 829-837.

25. Pucci B, Giordano A (1999) Cell cycle and cancer. Clin Ter 150, 135-141.

26. Ekholm SV, Reed SI (2000) Regulation of G(1) cyclindependent kinases in the mammalian cell cycle. Curr Opin Cell Biol 12, 676-684.

27. Barr AR, Heldt FS, Zhang T, Bakal C, Novak B (2016) A dynamical framework for the all-or-none G1/S transition. Cell Syst 2, 27-37.

28. Sonntag R, Giebeler N, Nevzorova YA, Bangen JM, Fahrenkamp D, Lambertz D, Haas U, Hu W, et al (2018) Cyclin E1 and cyclin-dependent kinase 2 are critical for initiation, but not for progression of hepatocellular carcinoma. Proc Natl Acad Sci USA 115, 9282-9287.

29. Aziz K, Limzerwala JF, Sturmlechner I, Hurley E, Zhang C, Jeganathan KB, Nelson G, Bronk S, et al (2019) Ccne1 overexpression causes chromosome instability in liver cells and liver tumor development in mice. Gastroenterology 157, 210-226.

30. Li X, Ma XL, Tian FJ, Wu F, Zhang J, Zeng WH, Lin Y, Zhang Y (2019) Downregulation of CCNA2 disturbs trophoblast migration, proliferation, and apoptosis during the pathogenesis of recurrent miscarriage. Am J Reprod Immunol 82, e13144.

31. Ruan JS, Zhou H, Yang L, Wang L, Jiang ZS Wang SM (2017) CCNA2 facilitates epithelial-to-mesenchymal transition via the integrin alphavbeta3 signaling in NSCLC. Int J Clin Exp Pathol 10, 8324-8333.

32. Khunsap S, Khow O, Suntrarachun S, Boonchang S (2020) A phospholipase A2 of Daboia siamensis venom suppressed expression of genes and proteins in MAPK pathway. ScienceAsia 46, 392-396.

33. Low HB, Zhang Y (2016) Regulatory roles of MAPK phosphatases in cancer. Immune Netw 16, 85-98.

34. Wagner EF, Nebreda AR (2009) Signal integration by JNK and p38 MAPK pathways in cancer development. Nat Rev Cancer 9, 537-549.

35. Cagnol S, Chambard JC (2010) ERK and cell death: mechanisms of ERK-induced cell death-apoptosis, autophagy and senescence. FEBS J 277, 2-21.

36. Wang SN, Lee KT, Tsai CJ, Chen YJ, Yeh YT (2012) Phosphorylated p38 and JNK MAPK proteins in hepatocellular carcinoma. Eur J Clin Invest 42, 1295-1301.

37. Yasuda E, Kumada T, Takai S, Ishisaki A, Noda T, Matsushima-Nishiwaki R, Yoshimi N, Kato K, et al (2005) Attenuated phosphorylation of heat shock protein 27 correlates with tumor progression in patients with hepatocellular carcinoma. Biochem Biophys Res Commun 337, 337-342.

38. Swamy SG, Kameshwar VH, Shubha PB, Looi CY, Shanmugam MK, Arfuso F, Dharmarajan A, Sethi G, et al (2017) Targeting multiple oncogenic pathways for the treatment of hepatocellular carcinoma. Target Oncol 12, 1-10.

39. Siveen KS, Ahn KS, Ong TH, Shanmugam MK, Li F, Yap WN, Kumar AP, Fong CW, et al (2014) Ytocotrienol inhibits angiogenesis-dependent growth of human hepatocellular carcinoma through abrogation of AKT/mTOR pathway in an orthotopic mouse model. Oncotarget 5, 1897-1911.

40. Tan SM, Li F, Rajendran P, Kumar AP, Hui KM, Sethi G (2010) Identification of beta-escin as a novel inhibitor of signal transducer and activator 
of transcription 3/Janus-activated kinase 2 signaling pathway that suppresses proliferation and induces apoptosis in human hepatocellular carcinoma cells. J Pharmacol Exp Ther 334, 285-293.

41. Mohan CD, Bharathkumar H, Bulusu KC, Pandey V, Rangappa S, Fuchs JE, Shanmugam MK, Dai X, et al (2014) Development of a novel azaspirane that targets the Janus kinase-signal transducer and activator of transcription (STAT) pathway in hepatocellular carcinoma in vitro and in vivo. $J$ Biol Chem 289 , 34296-34307.

42. Baek SH, Lee JH, Kim C, Ko JH, Ryu SH, Lee SG, Yang WM, Um JY, et al (2017) Ginkgolic acid C 17:1, derived from Ginkgo biloba leaves, suppresses constitutive and inducible STAT3 activation through induction of PTEN and SHP-1 tyrosine phosphatase. Molecules 22, ID 276. 